\title{
Exploration of the difficulties of economic development and modernization of pastoral areas of the Qinghai-Tibet plateau, China
}

\section{Practical Experience and Enlightenment of the "Six-pronged Unification" Model in Gaize County, Ngari Prefecture, Tibet Autonomous Region}

\author{
Wang Yanzhong $\cdot$ Ning Yafang $\mathbb{D}$
}

Received: 2 February 2019 /Accepted: 1 March 2019 / Published online: 22 March 2019 (C) The Author(s). 2019 Open Access This article is distributed under the terms of the Creative Commons Attribution 4.0 International License (http://creativecommons.org/licenses/by/4.0/), which permits unrestricted use, distribution, and reproduction in any medium, provided you give appropriate credit to the original author(s) and the source, provide a link to the Creative Commons license, and indicate if changes were made.

\begin{abstract}
Gaize County, located in Ngari Prefecture of Tibet Autonomous Region (TAR) and known as the "roof of the roof of the world," is an area with the toughest production, living and working conditions in the country. During the past 40 years of reform and opening-up, leading farmers and herdsmen in pastoral areas to build a well-off society and to realize socialist modernization has always been the top priority for the work of party committees and government at all levels. In the new era, Gaize County has explored a "Six-pronged Unification" Model for collective economic cooperatives aimed at realizing the modernization of animal husbandry in the context of the prominent contradiction between human and land resources, the inefficiency of traditional nomadic production and the herdsmen's weak awareness of market-orientation and market participation. The "Six-pronged Unification" Model has improved the risk resistance mechanism for production in animal husbandry, improved the income of herdsmen and their ability to participate in marketization, and enhanced the social governance capacity and governance system in pastoral areas. The "Six-pronged Unification" Model is not only a vivid practice of poverty alleviation in poverty-stricken pastoral areas in
\end{abstract}

This paper is arranged according to the final report of the research group for Gaize County's 40-year development experience in reform and opening-up.

Y. Wang · Y. Ning $(\bowtie)$

Institute of Ethnology and Anthropology, Chinese Academy of Social Sciences, No.6 Blg,No.

27,Zhongguancun Nandajie Road,Haidian District, Beijing, China

e-mail: wangyanzhong01@163.com

Y. Ning

e-mail: ningyf@cass.org.cn 
China, but also an organic part of the building of a comprehensive well-off society and realizing the modernization of socialism with Chinese characteristics in the new era.

Keywords Tibet · Modernization of animal husbandry · Pastoral reform · Well-off society $\cdot$ Pastoral areas, animal husbandry and herdsmen

\section{Introduction}

Gaize County, located in Ngari Prefecture of Tibet Autonomous Region (TAR) and known as the "roof of the roof of the world," is an area with the toughest production, living and working conditions in the country. In the new era, Gaize County has explored a "Six-pronged Unification" Model for collective economic cooperatives aimed at realizing the modernization of animal husbandry in the context of the prominent contradiction between human and land resources, the inefficiency of traditional nomadic production and the herdsmen's weak awareness of market-orientation and market participation. The "Six-pronged Unification" Model has improved the risk resistance mechanism for production in animal husbandry, improved the income of herdsmen and their ability to participate in marketization, and enhanced the social governance capacity and governance system in pastoral areas. The "Six-pronged Unification" Model is not only a vivid practice of poverty alleviation in poverty-stricken pastoral areas in China, but also an organic part of the building of a comprehensive well-off society and realizing the modernization of socialism with Chinese characteristics in the new era.

\section{Tortuous development of reform and opening-up in Gaize County}

\section{Weak development baseline of Gaize County}

Located in Ngari Prefecture of TAR (known as the "roof of the roof of the world"), Gaize County is an area with the toughest production, living and working conditions in Tibet and even in the whole country, due to its average elevation of 4700 $\mathrm{m}$ and minimum elevation of $4356 \mathrm{~m}$, as well as its thin air and dry, cold climate. Given the large area but small population, the county has low population density and thus has a poor development baseline The total land area of the county is $136,000 \mathrm{~km}^{2}$, including the grassland area of $78,706 \mathrm{~km}^{2}$. The coverage rate of forests is $5.82 \%$, and the coverage rate of wetlands is $3.51 \%$. The total area of grasslands is not small. Affected by the monsoon climate and geographical environment of arid plateau, however, the grassland quality is poor. The county is a typical poverty-stricken area with causes ranging from an annual average temperature below $0{ }^{\circ} \mathrm{C}$, an average precipitation of less than $200 \mathrm{~mm}$,(Hua et al. 2010) an arid and windy climate, a large difference in day and night temperatures, scarce vegetation, low carrying capacity of pastures, and both the stock and the supply of livestock being small. At the beginning of the liberation of Tibet, the county had a 
population of less than 10,000 people. ${ }^{1}$ As of the end of 2017 , Gaize County had a total population of 25,852 people. Restricted by the harsh natural environment, the residents of the county have long relied on animal husbandry for their livelihood. As a county purely supported by animal husbandry with limited transportation and difficulties in securing a livelihood, social undertakings such as education and health care in the county have lagged behind other areas. Affected by factors such as residential dispersion, the production needs of animal husbandry, and a lack of teaching facilities and teachers, the proportion of school-age children attending school is very low. In terms of social services on the whole, Gaize County has prominent problems due to its harsh natural environment, poor production and living conditions and insufficient social and public services including education and health care. In the long term, the life expectancy in the county is only 50 years old. ${ }^{2}$ At the end of the 1950s, the county began its democratic reforms, and since then Party and grassroots organizations have gradually improved. It is in the midst of this harsh environment and conditions that the county has undergone a difficult exploration of modernization under the leadership of the Communist Party of China (CPC).

\section{Exploration of modernization since the reform and opening-up}

The convening of the Third Plenary Session of the 11th CPC Central Committee in the year 1978 kicked off the prelude to China's reform and opening-up. Although Gaize County is located in the plateau hinterland of the western frontier region of China, and the reform and opening-up in the county coincided with the last stage of national reform and opening-up, the county has carried out reform and opening-up in the same way as other regions of the country, and constantly explored the practice to realize modernization of the county in line with that process. The path of reform in the county is similar to that of the agricultural areas throughout the mainland, but has different foci as well. The similarity lies in the delegation of operation autonomy. In 1980, the production responsibility system featuring "five fixed indicators and one award" (fixed pastures, fixed herds, fixed output, fixed remuneration, and reward for outperformance) was comprehensively promoted to improve the production enthusiasm of grassroots production organizations and herders. In 1984, people's communes were removed and townships were built; the family business responsibility system was implemented; and the "two long-term unchanged independent operation" policies were carried out (the land was returned to the households, with independent operation unchanged in the long

\footnotetext{
${ }^{1}$ Gaize County lacked reliable historical demographic data and issued some demographics successively after the peaceful liberation in 1951. In 1962, the county (including Cuoqin County of $23,000 \mathrm{~km}^{2}$ ) had a total of 10,879 people in,738 households. In 1970, Cuoqin County was set up and consisted of 4 districts and 21 townships, which were transferred out from Gaize County. In 1971, the population of Cuoqin County was 6312 people in 1547 households and the population of Gaize County was 8265 people in 2028 households. See the Local Records Compilation Committee of Gaize County: Records of Gaize County (Volume 1) (not yet officially published), November 2017, P8.

${ }^{2}$ Local Records Compilation Committee of Gaize County: Records of Gaize County (Volume 1) (not yet officially published), November 2017, P20.
} 
run; the livestock was owned by households for private cultivation, with independent operation unchanged in the long run). This basically changed the collective operation model of the people's communes established since the democratic reform and restored the traditional family operation system. The difference lies in the following: herdsmen in Gaize County, a special plateau-based animal husbandry area, still implement the collective pasture system, under which they use pastures according to traditional grazing habits with a pastoral operation group as a unit. The county began to build net fences for pastures in 1998, carried out the pilot contracted responsibility system for grasslands in 2005, and basically completed the contracted responsibility system for pastures in 2006. In 2008, the county carried out the pilot program for pastures in Oma Township, in summer and autumn, in accordance with the principle that pastures are publicly owned and the use of pastures is allocated to households for independent operation over the long term, and the county has completed the work relating to contracted operation of pastures. In response to new problems arising after the contracted operation of pastures, the county established eight economic cooperation organizations for farmers and herdsmen in 2009 as a link to the development of animal husbandry. ${ }^{3}$ The State has given strong support to contracted reform and ecological environment protection of pastures in pastoral areas, and subsidies for pastures according to the family population and area of pastures. In response to Tibet's special development environment, the State has implemented certain special preferential policies during the process of reform and opening-up. For example, in accordance with the spirit of the First Tibet Work Forum of the Central Government in 1980, the animal husbandry tax was exempted; the task of apportioning workers was abolished; and the basic living supply for urban workers and residents was guaranteed. In 1984 and 1994, the Second and Third Tibet Work Forums of the Central Government also implemented a series of measures to ensure that policies remained unchanged and to expand aid, respectively, hoping that Tibet could gradually narrow the gap with the national development level. These special preferential and supportive policies have been continuously implemented to this day, and the county is also the beneficiary region of these policies.

Since reform and opening-up, the scale of the county's economy has constantly expanded; the types of industries have become increasingly diversified; and the employment structure and economic structure have continued to undergo adjustments and changes. During the "12th Five-year Plan" period(2011-2015), the county had a total of 223 planning projects with a total investment of RMB1,602,469,000 and has completed 217 projects (investment of RMB1, $553,469,000$ ), including 51 infrastructure projects (investment of RMB284, 030,700), 50 agricultural and animal husbandry projects (investment of RMB150,113,100), 33 educational projects (investment of RMB84,484,140), 14 health care projects (investment of RMB26,262,700), 10 water conservancy projects (investment of RMB93,905,200), 10 environmental protection projects (investment of RMB10,725,960), 11 work-for-the-dole projects (investment of

\footnotetext{
${ }^{3}$ Local Records Compilation Committee of Gaize County: Records of Gaize County (Volume 2) (not yet officially published), November 2017, Section II, Chapter I, Part VII.
} 
Table 1 Economic

Development of Gaize

County, 1980-2017

Source: arranged according to the Historical Data Assembly of Gaize County in 1990 2017, the 2016 Statistical Yearbook of Gaize County, the 2017 Statistical Yearbook of Gaize County and government work reports for previous years provided by the Bureau of Statistics of Gaize County

\begin{tabular}{|c|c|c|c|c|c|}
\hline Year & $\begin{array}{l}\text { Population } \\
\text { (person) }\end{array}$ & $\begin{array}{l}\text { Local } \\
\text { financial } \\
\text { income at } \\
\text { corresponding } \\
\text { level (RMB) }\end{array}$ & $\begin{array}{l}\text { Rural } \\
\text { GDP } \\
\text { (RMB) }\end{array}$ & $\begin{array}{l}\text { Per capita } \\
\text { income of } \\
\text { farmers } \\
\text { and } \\
\text { herdsmen } \\
(\mathrm{RMB})\end{array}$ & $\begin{array}{l}\text { Proportion } \\
\text { of the } \\
\text { primary } \\
\text { industry } \\
(\%)\end{array}$ \\
\hline
\end{tabular}

Proportion of the secondary industry (\%)

\begin{tabular}{llllll}
\hline 1980 & 9988 & $250 \mathrm{~K}$ & $2.06 \mathrm{M}$ & $1.87 \mathrm{M}$ & - \\
1985 & 11,729 & $160 \mathrm{~K}$ & $5.73 \mathrm{M}$ & $4.43 \mathrm{M}$ & - \\
1990 & 13,400 & $2.44 \mathrm{M}$ & $9.38 \mathrm{M}$ & $6.19 \mathrm{M}$ & 93.5 \\
1995 & 14,634 & $3.5 \mathrm{M}$ & $30.59 \mathrm{M}$ & $14.17 \mathrm{M}$ & - \\
2000 & 16,104 & $4 \mathrm{M}$ & $30.33 \mathrm{M}$ & $15.99 \mathrm{M}$ & 77.2 \\
2005 & 19,895 & $7.56 \mathrm{M}$ & $73.12 \mathrm{M}$ & $18.55 \mathrm{M}$ & 68.9 \\
2010 & 22,284 & $6.46 \mathrm{M}$ & $104.79 \mathrm{M}$ & $34.55 \mathrm{M}$ & 54.0 \\
2015 & 25,291 & $23.44 \mathrm{M}$ & $349.68 \mathrm{M}$ & $79.4 \mathrm{M}$ & 36.4 \\
2016 & 25,349 & $23.4 \mathrm{M}$ & $349.68 \mathrm{M}$ & $56.3 \mathrm{M}$ & 35.1 \\
2017 & 25,852 & $26.21 \mathrm{M}$ & $302.15 \mathrm{M}$ & $97.69 \mathrm{M}$ & 38.8 \\
\hline
\end{tabular}

0.04

5.4

12.4

8.9

15.2

21.2

15.1

RMB10,830,000), 9 stability maintenance projects (investment of RMB20, 552,110 ), and 29 transportation projects (investment of RMB872,564,900). ${ }^{4}$ These construction projects were not focused on animal husbandry, but on the secondary and tertiary industries, and on infrastructure construction and the provision of public social services. The survey found that animal husbandry was still the pillar industry of the county, and that most of the herdsmen were still engaged in grazing and rough processing of livestock products, but the proportion of the primary industry declined gradually. With the expansion of the investment areas of construction projects, the county's employment channels and urban and rural residents' income patterns were also increasingly diversified. In each year from 2014 to 2017, the county's labor income obtained through transfer of employment was RMB3,090,000, RMB6,814,000, RMB7,885,000 and RMB13,910,000, respectively. ${ }^{5}$ Since the onset of reform and opening-up, the county's economic output and per capita income have continued to grow. In 2017, the per capita net income of farmers and herdsmen was 52 times higher than that in 1980, adjusting for inflation (see Table 1).

Compared with the whole country, the development scale and income growth rate of Gaize County were not very prominent. However, compared with the small-scale nomadic tribal society that lives by the water grass, the development and changes of Gaize County since reform and opening-up have been astonishing. In the survey, many cadres and members of the general populace said that such

\footnotetext{
${ }^{4}$ Command Office of Gaize County for Poverty Alleviation: Plan on Further Poverty Alleviation in Gaize County, Ngari Prefecture of Tibet [Z], October 2017.

${ }^{5}$ Source: arranged according to the summary of the work of the Human Resources and Social Security Bureau of Gaize County from 2014 to 2017.
} 
development and changes of the county are mainly reflected in two aspects: First, earth-shaking changes have taken place in the realm of material life. Regardless of transportation, communication, or housing for herdsmen and other aspects of daily life, the current material conditions of Gaize County have changed. Second, the social realm has developed significantly. Education, modern medical and health care undertakings, public cultural undertakings, government public services, etc. have experienced development from non-existence to the beginnings of such provisions, and from the beginnings to perfection in the past 40 years of reform and opening-up.

\section{Problems in the exploration process of reform and opening-up}

Gaize County has made enormous achievements in the reform and opening-up of the county over 40 years, and the earth-shaking changes have laid a certain foundation for the realization of modernization. However, in the process of reform exploration and development, there are also some problems and setbacks, which are mainly reflected in five aspects. First, traditional animal husbandry has growth limits. Although the theoretical livestock carrying capacity of Gaize County is 1.2 million, the actual available area of pastures in the county cannot bear the theoretical livestock carrying capacity. On the one hand, pests such as Achnatherum inebrians, livestock diseases and climate disasters restrict the availability of pastures. ${ }^{6}$ On the other hand, the rapid proliferation of wild animals in the Chang Tang Nature Reserve poses a threat to livestock and grass, and the contradiction between the development of animal husbandry and wildlife protection increases. In addition, the area of artificial grass and grass yield are limited, and large-scale planting cannot be achieved. Second, increasing environmental protection efforts have greatly restricted the development of the mining industry. The mineral resources in Gaize County are very rich, with mineral resources mainly including gold, boron lithium, copper and salt resources. As early as 1992, Gaize County began to exploit mineral resources in the county. Mining continued until 2005, when the county strengthened the protection of the ecological environment in accordance with the relevant provisions of Tibet Autonomous Region and Ngari Prefecture, strengthened the management of mining of mineral resources in the county, and completely stopped gold mining. The promotion of the Plan on Ecological Security Barrier Protection and Construction in Tibet (2008-2030) and the initiative of "developing a beautiful Tibet" also imposed many constraints on the exploitation of mineral resources in Gaize County. Third, the quality of the labor force is not high; there are not many job opportunities; and it is difficult to go out to work and do business. Traditionally, the county's herdsmen mainly carry out their family-based nomadic

\footnotetext{
${ }^{6}$ Achnatherum inebrian, whose botanical name is glacial Oxytropis, is a poisonous grass plant. Chronic accumulation poisoning occurs within 2-3 months after the animals are fed. The mortality rate of poisoning is as high as $85 \%$. From 1987 to 2000, there were 401,500 livestock poisoned by achnatherum inebrians and 336,200 livestock that were dead in the county, resulting in a direct economic loss of RMB51,690,000. Local Records Compilation Committee of Gaize County: Records of Gaize County (Volume 2) (not yet officially published), November 2017, Section VI, Chapter I, Part VII.
} 
production as nomadic rotation of animals requires the occupation of a large number of family laborers and the pastoral population is only able to access education for short periods. Most of the pastoral labor force have the skills to practice traditional animal husbandry, but lack the labor skills to participate in modern agricultural production, or to go out to work and engage in service industries. Fourth, the limitations posed by decentralized operations undertaken by separate households have become increasingly prominent. The implementation of the household production responsibility system allows some herdsmen who have fewer livestock or absolutely no livestock to leave the pastures and no longer engage in animal husbandry production. With the diversification of employment patterns, the income of herdsmen has been increasingly unstable, the income gap between herdsmen has gradually expanded, and the population in a state of chronic poverty has gradually increased. Herdsmen in households have a weak position in the market competition. They lack the market pricing power over livestock products and lack brand awareness. It is difficult for them to counter the risk of market fluctuations and increase income. Fifth, the pressure on social stability in special areas is outstanding. Tibet is a special, frontier, ethnic region and is at the forefront and frontline of the anti-secession struggle. The majority of herdsmen in Gaize County are deeply affected by traditional religion and culture. They have a low level of education and strong religious beliefs and lack the awareness and ability to resist the division and damage caused by the hostile forces of Western countries, the surrounding forces against China, and the Dalai clique. With the strong contrast between the rapid development of the whole country and the difficulty of local poverty alleviation, it is easy for herdsmen to be affected by the external environment that can cause an adverse impact on social stability.

It is the existence of the above-mentioned problems and setbacks that inspire the cadres and masses in Gaize County to reflect on how to explore the modernization road in the new era, to respond to the transformation of major social contradictions, and to solve the problem of insufficient and unbalanced development faced by the county. In the plateau pastoral areas, exploring the path and road of the modernization of animal husbandry is of great significance, but there are also many difficulties and challenges. Under this background, guided by the Four-Pronged Comprehensive Strategy of the CPC Central Committee, Qianggu Village, Oma Township of Gaize County has explored and formed the "Six-pronged Unification" Model for cooperative animal husbandry with the uniform operation of collective economy as a core characteristic, and achieved remarkable results. This exploration has provided a breakthrough for poverty-stricken pastoral areas to alleviate poverty and strive for a relatively comfortable life, and has accumulated valuable experience for the modernization of plateau pastoral areas.

Exploration of the modernization of animal husbandry in Gaize County in the new era: An analysis based on the "six-pronged unification" model

Since the 18th CPC National Congress in the year 2012, the Central Government has successively adopted a series of special supportive policies for Tibet, Tibetan areas of four provinces, and "three regions and three prefectures." The State and 
developed regions, and large central and state-owned enterprises, have also given multi-dimensional assistance to Tibet, which provides Gaize County with a rare development opportunity for poverty alleviation and prosperity and for striving for a well-off society. In the process of implementing the above-mentioned policies, the county gives full play to the leadership role of Party organizations at all levels, aims at increasing the income of herdsmen and maintaining social stability in Tibetan areas, focuses on promoting the level of the primary industry and the industrialization of animal husbandry, actively instructs herdsmen to explore and develop various types of professional cooperative economic organizations, broadens the channels for herdsmen to enter the market, enhances the herdsmen's ability to participate in the market, enhances their ability to increase their income, and accelerates the poverty alleviation in deeply poverty-stricken areas and the building of a comprehensive well-off society.

\section{Development process of professional economic cooperatives in Gaize County}

Since 2010, the number of professional economic cooperatives in Gaize County has increased from 8 to 58 in 2016. The number of participating cooperatives and registered capital have increased by several times, and operating income has also increased steadily (see Table 2).

In 2012, Gaize County tried to adopt various models for the operation of cooperatives, such as "association plus herdsmen," "base plus association plus herdsmen," "enterprise plus association plus herdsmen," "branch plus association plus herdsmen," "skilled persons plus association plus herdsmen." Since the entry into the new era, professional economic cooperation organizations in the county have been developing rapidly. In 2014, the county focused on accelerating the

Table 2 Development of Agricultural Cooperatives in Gaize County

\begin{tabular}{lllll}
\hline $\begin{array}{l}\text { Year } \\
\text { cooperatives }\end{array}$ & $\begin{array}{l}\text { Number of participating } \\
\text { cooperatives }\end{array}$ & $\begin{array}{l}\text { Registered capital } \\
\text { (RMB) }\end{array}$ & $\begin{array}{l}\text { Annual income } \\
\text { (RMB) }\end{array}$ \\
\hline 2010 & 8 & - & - & - \\
2011 & 15 & & - & - \\
2012 & 15 & 1515 & - & - \\
2013 & 56 & 4623 & $15.83 \mathrm{M}$ & $10.14 \mathrm{M}$ \\
2014 & 52 & 3441 & $15.67 \mathrm{M}$ & $10.39 \mathrm{M}$ \\
2015 & 60 & 8878 & $89.54 \mathrm{M}$ & $11.38 \mathrm{M}$ \\
2016 & 58 & 8588 & $89.54 \mathrm{M}$ & $16.74 \mathrm{M}$ \\
2017 & 31 & 1680 & $36.87 \mathrm{M}$ & $18.75 \mathrm{M}$ \\
\hline
\end{tabular}

(1) Since a household may participate in multiple cooperatives at the same time, the total number of households participating in cooperatives exceeds the actual number of households in the county; (2) With the further promotion of pastoral reform, the Party committees and local governments of Ngari Prefecture and Gaize County raised requirements for the standardized operation of agricultural cooperatives, and strengthened the rectification of agricultural cooperatives with irregular operation. Therefore, the number of agricultural cooperatives officially registered in the county, and the number of participating households and registered capital decreased in 2017

Source: arranged according to the summary of the work of the Agriculture and Animal Husbandry Bureau of Gaize County over years 
standardized development of professional economic cooperatives for farmers and herdsmen and improved the organization of farmers and herdsmen entering the market. The types of economic cooperation organizations throughout the county increased significantly. In 2014, there were 52 professional economic organizations in the county, including 27 construction organizations, 13 catering service organizations and convenience stores, 5 planting and breeding organizations, 3 folk handicraft organizations and 4 mechanical repair organizations. These professional economic cooperation organizations earned more than RMB10,395,000 in the whole year, and distributed the annual dividend of around RMB3,180,000.(8) In 2015 , there were 31,068 members in 60 professional economic cooperation organizations in the county (one person may participate in multiple cooperatives, so the total number of members exceeded the total population of the county), and the operating income was RMB11,388,300, representing a year-on-year increase of $265.2 \%$. In 2016, the operating income of 58 professional economic cooperation organizations in the county was RMB16,744,600, representing a year-on-year increase of $47 \%$. The county has achieved certain results in the exploration of the development of professional economic cooperation organizations, but these organizations also faced many difficulties in the early years of operation. For example, the degree of organization for production, processing and sales of agricultural and livestock products was low; the operation of the organization was not standardized; the mechanism was not perfect; the cohesiveness was not strong; the market system of agricultural and livestock products was not perfect; the sales network was loose; there was a lack of circulation enterprises and professional brokers; and sales channels were not smooth. These problems made professional economic cooperation organizations play a limited role in improving the degree of local marketization, improving the utilization efficiency of animal husbandry resources and increasing the income of herdsmen.

"Six-pronged unification" model for professional economic cooperation organizations in Qianggu Village ${ }^{7}$

After the early stage exploration and practice by the professional economic cooperation organizations, the concepts and ideas for development of the collective economy have been gradually accepted by the majority of the cadres and residents in Gaize County, but the disadvantages of the scattered economic cooperatives also needed to be considered. In 2015, the county included Qianggu Village, in Oma Township, as the pilot village for pastoral reform. The theme of the reform was to expand the village's collective economy by means of cooperatives. In response to previous problems such as small-scale individual pastoral cooperatives, extensive operation costs, limited ability to guard against market risks and weak driving ability, the county integrated various professional cooperative organizations for

\footnotetext{
${ }^{7}$ Qianggu Village, Oma Township is located $50 \mathrm{~km}$ west to Gaize County. After the districts were removed and the townships were merged in 1999, the village party committee and the villagers' committee were established. There are 4 villager groups under the jurisdiction of Qianggu Village (Are, Sabu, Nimalong and Qusongma). There are 301 people in 86 households, including 60 poverty-stricken people in 21 households.
} 
scattered herdsmen to establish a collective economic cooperative for herdsmen in the village.

The collective economic cooperative for herdsmen in Qianggu Village, in accordance with the voluntary principle, encouraged and instructed the masses to participate in the operation of the cooperative in the form of livestock shares, labor shares, grazing by several households and pasture circulation. The cooperative worked according to the operation model of "unified labor arrangement, unified management of pastures, unified purchase and sale of livestock products, unified distribution of operating income, unified support for persons without working capacity and seniors without family, and unified scores for students in school" (hereinafter referred to as "Six-pronged Unification" Model), and promoted the transformation of production in traditional extensive animal husbandry to scientific intensification and economy of scale. In 2015, there were 71 households with 256 members in the collective economic cooperative for herdsmen in Qianggu Village (the remaining 15 households were individual businesses operating outside all year round or households without livestock whose registered permanent residence was in Qianggu Village). The business scope included one construction team, one yak breeding base, two collective teahouses, two collective stores, one agricultural machinery repair shop and one demonstration and promotion base for Xiangxiong Semifinewool sheep.

1. Main content of the "Six-pronged Unification" Model for operation in Qianggu Village

(1) Collectivization and scale of production materials

The idea of the collective economic cooperative for herdsmen in

Qianggu Village was to first realize the collectivization and scale of the animal husbandry production materials of the whole village by means of "livestock shares and labor shares." By holding a membership meeting, the cooperative determined a per capita amount of 14 sheep (sheep unit) as the base livestock share in Qianggu Village, with $40 \%$ designated as individual shares and $60 \%$ collective village shares. At the same time, the idle pastures without livestock-owning households, as well as individually owned businesses and relocated households in the village were transferred to the cooperative on the principles of legality, willingness and compensation, so that the idle pasture resources in the village were effectively utilized. The transfer of pastures not only avoided the phenomenon of poor management or inadequate protection of pastures as well as waste of pasture land, but also provided certain economic income for households without livestock, individually owned businesses and relocated households in the village.

(2) Standardization of the cooperative's management work

The collective economic cooperative for herdsmen in Qianggu Village has established rules and regulations such as the Administrative Measures for the Cooperative, the Labor Vouchers and Scoring 
Standards for the Participating Members of the Cooperative, and the Application for the Registration of Entering Members of the Cooperative, which clarify the organizational form, and membership obligations and rights. A manager is collectively elected to undertake daily management matters. These practices have further standardized the internal operation and management mechanism of the cooperative, strengthened the cultivation of management talent of the cooperative, and improved the organizational management level and the ability of members to participate in public social governance.

(3) Integration and utilization of external aid resources

In order to improve the utilization efficiency of external supportive resources, Qianggu Village has established a whole-process integration mechanism from plan preparation and project reporting to fund use by adhering to the principles of "coordinating locations with plans, coordinating projects with locations, and coordinating funds with projects." Since 2015, agriculture, animal husbandry, water conservancy, poverty alleviation and other agriculture-related projects in the village have been integrated involving funds of more than RMB3.28 million that have been used for standardizing the construction of infrastructure such as cowsheds, sheepfolds and pruataculture. In addition, the cooperative will integrate the grassland ecological protection subsidies for members to build a new sand washing plant. Thanks to the integration of project funds and the self-owned funds of the members, the operation of the cooperative has been guaranteed by the county government, and the cooperative, with its increased capital, has been approved for increased bank loans.

(4) Standard accounting of labor vouchers for labor tasks

In order to enhance the enthusiasm of the members to participate spontaneously in the cooperative's labor activities, by learning from the labor voucher system during the people's commune period, and in combination with the actual situation of the industries in the village, Qianggu Village has established the concept of more gains for more labor, and implemented the "uniform labor arrangement" and the mechanism for calculating labor vouchers. According to the membership meeting of the cooperative, the scoring standards are set according to different types of work: 17 points for the work of the construction team for 1 day, 16 points for herding sheep for 1 day, 9 points for herding cattle for 1 day, 6 points for milking ewes or cows for 1 day, 25 yuan for slaughtering 1 sheep, 100 yuan for slaughtering 1 head of cattle. For school-age children and students in school, the assessment criteria are set up separately. Each student in school is given 100 points. In order to guarantee the study time, the cooperative does not arrange for school-age children and students in school to participate in the cooperative's labor activities, but school-age children who do not 
attend school or fail to go to school without reason cannot participate in the distribution of dividends by the cooperative at the end of the year.

The establishment of the labor voucher system has brought the concept of more gains for more labor to the people. At the same time, it has provided basic guarantees for the students of the member families to fully enroll in school, and has relieved the worries of the members that prevented their children from receiving education due to the lack of labor in the family. This system is a good example for Gaize County's poverty alleviation, supporting will and intelligence, and plays a good role in demonstrating the concept and behaviors of those villagers waiting for state aid funds, relying on higher-level financial allocations, and asking for poverty alleviation funds.

(5) Unified distribution and sharing of labor income according to work Qianggu Village distributes the income of the cooperative according to labor in a unified manner so as to realize the income distribution mechanism under which everyone participates in labor and shares labor income. The specific distribution method: $82 \%$ of the cooperative's year-end net income is distributed to the members, $4 \%$ is used for supporting the laborless and widowed elderly in the village, $6 \%$ is the basic compensation of the cooperative's management personnel, and the remaining $8 \%$ is reserved for the cooperative's venture capital and working capital. At the same time, the village committee strictly implements the village affairs disclosure system and publicizes all the accounts of the collective economy, which greatly improves the villagers' trust in the "two committees."

2. Initial effect of the "six-pronged unification" model in Qianggu Village

(1) The income of villagers in Qianggu Village has increased significantly. From 2013 to 2017, the annual per capita income of the members (excluding the transfer income under policies) was RMB7,234, RMB8,215, RMB10,200, RMB13,094.58 and 14,701.73, respectively. The enthusiasm and initiative of the members to participate in the unified labor activities have been significantly enhanced.

(2) The scale of operation of the collective economy continues to expand. The number of yaks in the breeding base in Qianggu Village increased from 74 in 2012 to 314 in 2017, and the number of Xiangxiong Semifinewool sheep increased from 403 to 803 . The working capital of the village's collective stores increased from RMB150,000 in 2014 to RMB500,000 in 2017. The area of pruataculture increased from $200 \mathrm{mu}$ in 2014 to $1000 \mathrm{mu}$ in 2017.

(3) The situation of diversified income generation by surplus labor has basically taken shape. After animal husbandry realized large-scale and unified operation, many surplus laborers set up labor income generation teams. In 2017, 78 laborers in Qianggu Village were freed from pure animal husbandry activities, and engaged in the construction of roads, road hardening, fences, affordable housing, greenhouses or other aspects, or engaged in service industries and other industries. Breakthroughs were 
made from single income to diversified income. Surplus labor created income of RMB1,282,600.

(4) The income distribution method for dividends by shares has activated the desire of herdsmen for active labor. The unified income distribution method, in which income is distributed and shared according to labor, has mobilized the awareness of the members of the cooperative to work diligently and earn income actively. In accordance with the principle that " $82 \%$ of pure income is distributed to members," in 2016 , the average dividend distributed to members with shares was RMB15,501, and the maximum and minimum dividend was RMB54,240 and RMB5,971, respectively. In 2017, the average dividend distributed to members with shares was RMB18,903.9, and the maximum and minimum dividend was RMB59,318.15 and RMB5,365, respectively.

(5) Newly collectivized economic security has been added for elderly care and children's education. The cooperative provides a unified income guarantee for the unemployed and widowed elderly in the village. In 2016, 22 unemployed and widowed elderly residents in the village were paid RMB3,734 per person, and in 2017, each person received RMB4,388. This approach avoids condemning jobless and widowed elderly people to poverty. In order to thoroughly implement the national education-related policies, starting with encouraging and supporting sending children to school, the cooperative determines to provide each student in school with labor vouchers of 100 points. In 2016, one labor voucher was equivalent to RMB11.36, and thus each student in school was given RMB1,136; in 2017, one labor voucher was equivalent to RMB11.5, and each student in school was given RMB1,150. In general, the redistribution of income independently organized by Qianggu Village has strengthened the people's livelihood security function of the village's collective, provided supplementary support for herdsmen from the village's collective, and built a multi-level social security system.

(6) Pasture resources in the village have been effectively utilized. The collective economy operating on a unified basis has led to the transfer of pastures in the village, so that idle pastures can be effectively utilized. This not only increases the scale and capacity of the animal husbandry of the whole village, but also increases the income of the transferred households. In 2017, the total amount involved in the transfer of pastures in the whole village was RMB47,935, and the average annual rent for the transfer of pastures obtained by each household was RMB3,195.67.

In general, in 2017, the cooperative generated total income of RMB3,764,000. Specifically, the mass construction team earned RMB858,000; the income generated by the yak breeding base and the demonstration and promotion base for Xiangxiong Semifinewool sheep and other animal husbandry income amounted to 
RMB1,268,000; collective teahouses, collective stores and artificial grass planting earned RMB1,472,000; other income amounted to RMB166,000; the total income increased by $21.8 \%$ as compared with that in 2016 .

\section{Results and discussion}

When promoting the pilot reform of pastoral areas, in addition to the "Six-pronged Unification" Model in Qianggu Village, Gaize County has also implemented the models such as "joint grazing" and "pastures supporting each other" with the Nianta Team, in Zhumari Village, Gumu Township. Different townships also carry out pilot programs for the development of the collective economy on the basis of the overall requirements for pastoral reform by reference to the programs in Qianggu Village and Nianta Team of Zhumari Village. However, judging from the current operational effects of various collective economies, the "Six-pronged Unification" Model in Qianggu Village is a relatively effective modernization path for those engaged in Tibet's animal husbandry. The unified operation of collective economic cooperatives involves the integration of aid resources, labor arrangements, income distribution, management of pasture utilization and protection for the young and the elderly, and plays a fundamental role in promoting the emancipation of herdsmen's thinking, the transformation of traditional nomadic production methods, the optimal allocation of production materials, income distribution and the modernization of animal husbandry. Since the 18th CPC National Congress, Gaize County has actively promoted the "Six-pronged Unification" reform model in Qianggu Village, which is the direct manifestation of the Chinese Communists' remaining true to their original aspiration for the people in the new era. Therefore, the experience in the operation of collective economic cooperatives explored by the county is worth summarizing, and is of great theoretical and practical significance to further modernization.

\section{Practical experience}

(1) The leading and demonstration role of party organizations is the fundamental guarantee for the healthy development of cooperative economic organizations

The pilot pastoral reform in Gaize County has been highly valued and supported by Party organizations at all levels. In accordance with the requirements of the reports, Opinions of the Tibet Autonomous Region on Promoting Rural Reform and Development in an All-round Way and the Circular of the Office of the CPC Committee of Ngari Prefecture on Forwarding the Official Reply to the Experimental Plan for the Rural Reform at the Level of Autonomous Region in Cara District, Changdu City and Gaize County, Ngari Prefecture, the Party committee and government of Gaize County has formulated the Implementing Proposals for Pastoral Reform in Gaize County and issued various rules and regulations. At the 
same time, the leaders of the party committee and the government of the county have repeatedly made investigation and given direction at the village to further promote the work of pastoral reform. In the specific operation of the cooperative, the Party committee and government office of the village set up a number of Party groups according to the business scope of the collective economic cooperative, giving full play to the vanguard and exemplary role of Party members and realizing that Party members and the masses carry out the same labor activities. During the common labor activities, on the one hand, Party members teach collective members production and management skills and lead them to emancipate their minds; on the other hand, Party members take the initiative to play a leading role in the distribution of income, to give more benefits to the people and help other herdsman families achieve faster income growth. In this process, the prestige of the Party organization has been significantly strengthened, and the people's trust in the party organization has greatly improved.

The Party organization has played an active and leading role in the modernization reform of animal husbandry in Gaize County because the proportion of Tibetan elites joining the Party is high. The overlapping of local elites and Party members can more effectively combine the resources invested by the government with local resources, and effectively combine regional development with the benefits of herdsmen to achieve a win-win situation. This is the experience that Gaize County should continue to carry forward in deepening the reform and opening-up of the new era.

(2) Unified operation of the collective economy enhances community resilience in relation to economic and social risks

The "Six-pronged Unification" Model for the collective economy in Gaize County has changed the nature of production methods utilized by traditional nomadic households. Organized and large-scale production methods in animal husbandry have changed the situation that made it difficult for individual herdsmen to recover from or avoid natural disasters in the past and the difficulty of disaster relief after the occurrence of such natural disasters. The changes in the production risk resilience mechanism have led to changes in the herdsmen's life risk resistance mechanism. On the one hand, concentrated living and production can better organize and mobilize public participation, greatly reducing the costs of disaster relief and improving disaster relief efficiency. On the other hand, the unified support for those not engaged in labor and for widowed elderly under the "Six-pronged Unification" Model has added an old-age poverty risk protection mechanism for the herdsmen at the livelihood level. In general, the operation model of the collective economy has woven a comprehensive risk-resistance network for the modernization of animal husbandry in Gaize County, improved the efficiency of animal husbandry production, enhanced the confidence of herdsmen in active production, and provided the modernization reform of animal husbandry with strong supporting services. 
(3) The collective economy is a comprehensive carrier that undertakes economic and social governance functions

The collective economic cooperative in Gaize County has not only realized economic functions, but also played many social governance functions in actual operation. The development of the collective economy is in line with the local development expectations of the Party committees and governments at all levels. It is also a positive exploration for herdsmen in Gaize County to survive and seek development in the market under restrictions. From the perspective of economic production functions, the unified operation of the collective economy has improved the risk resistance mechanism and achieved income growth. From the perspective of income distribution functions, the concept of common prosperity has been strengthened through the income distribution system of the collective economy, and fully reflects the sharing of the reform and development results. From the perspective of social functions, compared with traditional people's communes, the past people's communes mainly served the planned-economy system and national development goals. Under the socialist market economic system, the "Six-pronged Unification" Model of collective economy organically integrates the economic interests of the herdsmen with the socially harmonious development of the pastoral areas, and achieves the organization of the herdsmen entering the market. At the same time, collective economic cooperatives have played a cohesive role in promoting traditional culture and forming a positive social atmosphere, and are effective carriers for practicing socialist core values. In addition, collective economic cooperatives have played a positive role in preventing the occurrence of "waiting, relying on and asking for support" and lack of support for the elderly, and can effectively manage religious activities. The "Six-pronged Unification" Model of collective economic cooperatives has a positive effect in preventing social risks, weakening social problems and preventing social derailment.

(4) Promoting the market-oriented development of animal husbandry with the path of organization and scale

Since undertaking reform and opening-up, Gaize County has made great progress in economic and social development by relying on the hard work of local cadres and citizens and the assistance of external resources. However, due to the remote geographical location and the deep-rooted concept of local traditional animal husbandry production, the marketization of the internal market in Gaize County is not high. The concepts such as not slaughtering livestock and not willing to sell livestock and using stock number as a measure of wealth have long restricted the enthusiasm and ability of herdsmen to participate in the socialist market economy. In order to improve internal marketization, Gaize County enhances the full integration and utilization of the herdsmen's external assistance resources through the unified operation of collective economy and by enhancing the organization of production activities in animal husbandry and the scale of animal husbandry products. In the exploration of organization and scale, 
the concept that "cadres are the best entrepreneurs" is fully embodied. In other words, Party and government organizations lead and instruct local people to complete marketization, rather than simply letting the people themselves explore the way to complete marketization.

(5) Further integration is carried out to enhance the comprehensive functions of collective economic cooperatives

Qianggu Village promotes pastoral reform according to local conditions.

The original yak breeding base, village collective stores, teahouses, construction teams, agricultural machinery repair stores, etc. will be integrated to jointly organize herdsmen's collective economic cooperatives and effectively turn resources into capital. At the same time, by fully seizing opportunities such as poverty alleviation through industry and accurate poverty alleviation through infrastructure construction, the cooperatives integrate and guide the surplus labor force to form construction teams to achieve labor income. This has not only improved the economic income of herdsmen, but also realized multi-format operations, and continuously enhanced the degree of participation by members in marketization and through increased working and labor skills.

(6) The virtuous circle within the "six-pronged unification" model promotes the improvement to social governance capacity

The "Six-pronged Unification" Model has facilitated synergy and cooperation between the aspects of production materials, labor, income distribution and mutual assistance guarantee. On the basis of carrying forward the excellent Tibetan traditional culture, the model has achieved the unity and mutual assistance of the members in production and life, and enhanced the cohesiveness of the cooperatives. The unified integration of production materials lays a foundation for large-scale operations. The unified deployment of the labor force improves the efficiency of unified operations. The income distribution concept of "more pay for more work" and the unified scoring standards for labor tasks have enhanced the concept of achieving prosperity through hard work and the endogenous development motivation. In addition, it has provided bottom guarantee for members as it has provided economic guarantees for the young and the elderly, relieved the worries of the members to participate in the unified operations, and enhanced the sense of acquisition, happiness and security of all members. It is the virtuous circle within the "Six-pronged Unification" Model that continuously improves the comprehensive social governance ability of Qianggu Village.

\section{Main conclusions}

The exploration of the "Six-pronged Unification" Model of the collective economic cooperatives represented by Qianggu Village is carried out in the realistic background of the contradiction between people and resources, the low efficiency of traditional independent household grazing production, the weak market awareness 
and ability of herdsmen and the difficulty in increasing income in Gaize County. The emergence of a unified collective economy has changed the risk resistance mechanism for production in animal husbandry in pastoral areas, improved the income of herdsmen and their ability to participate in marketization, deepened the diversificaiton of social division of labor in pure animal husbandry counties, and realized the modern transformation of herdsmen's production method from traditional pastoral nomadism to fixed-point farming and working. Guaranteed by the strong leadership of the party organization, the "Six-pronged Unification" Model has resulted in an active exploration of the modernization of the social governance capacity, production methods, and herdsmen's development concept in Gaize County as a Tibetan county engaged purely in animal husbandry. This positive exploration is precisely the concentrated manifestation of Tibet's insistence on "governing Tibet in accordance with the law, enriching the people and developing Tibet, constructing Tibet for posterity, rallying people's hearts, and solidifying the foundation" in the course of reform and opening-up.

At present, the modernization of animal husbandry in Gaize County is in its early stage, and adopting the "Six-pronged Unification" Model is in line with the historical and cultural background and current development conditions of the county. In actual operation, collective economic cooperatives have realized the cohesion of multiple functions in economic, social and political aspects through the generation and sharing of interests. This is an exploration of a "low-cost and highly-efficient" modernization model. Collective economic cooperatives are a kind of community with economic functions and certain social functions that are different in nature from ordinary enterprises. Such cooperatives are similar to the "state-owned enterprises" in rural areas (because they have assumed multiple functions). Therefore, the support given by the Party committee and government for the exploration of the "Six-pronged Unification" Model in Gaize County is in line with the socialist national conditions with Chinese characteristics and the self-development laws of the cooperatives. This kind of exploration has corrected some misconceptions about the functions of the cooperatives of the past, and has allowed for re-recognition that collective economic cooperatives are a kind of organization or community with externality. The externality of cooperatives on members, society, government and the market have laid a good foundation for realizing the modernization of animal husbandry and realizing the social governance capacity and modernization of the governance system in Gaize County. The exploration of the modernization of plateau practice of animal husbandry in Gaize County is an important part of the path of China's socialist modernization, and a new case for exploring the modernization of animal husbandry at high altitudes around the world.

Acknowledgements Not applicable

\section{Funding}

Not applicable 


\section{Availability of data and materials}

Not applicable

\section{Authors' contributions}

Both authors read and approved the final manuscript.

\section{Ethics approval and consent to participate}

Not applicable

\section{Consent for publication}

Not applicable

\section{Competing interests}

The authors declare that they have no competing interests.

\section{Publisher's Note}

Springer Nature remains neutral with regard to jurisdictional claims in published maps and institutional affiliations.

\section{Reference}

Wei, Hua, et al. 2010. A simulation study of the effects of climate change on vegetation physiology and its feed back effects in Gaize area. Plateau Meteorology 4: 875-883. 